\title{
Correction to: The Amsterdam Wrist Rules to reduce the need for radiography after a suspected distal radius fracture: an implementation study
}

\author{
Marjolein A. M. Mulders ${ }^{1}\left(\mathbb{D} \cdot\right.$ Monique M. J. Walenkamp $^{1}$ (D) Nico L. Sosef ${ }^{2}\left(\mathbb{C}^{\circ} \cdot\right.$ Frank Ouwehand $^{3}$. \\ Romuald van Velde ${ }^{4} \cdot$ J. Carel Goslings ${ }^{5}$. Niels W. L. Schep ${ }^{6}$ (])
}

Published online: 8 November 2019

(c) Springer-Verlag GmbH Germany, part of Springer Nature 2019

\section{Correction to: \\ European Journal of Trauma and Emergency Surgery https://doi.org/10.1007/s00068-019-01194-2}

The original version of this article unfortunately contained a mistake. The spelling of the J. Carel Goslings' name was incorrect. The correct information is given above.

The original article can be found online at https://doi.org/10.1007/ s00068-019-01194-2.

Marjolein A. M. Mulders

m.a.mulders@amsterdamumc.nl

1 Trauma Unit, Department of Surgery, Amsterdam UMC, Location Academic Medical Center, University of Amsterdam, P.O. Box 22660, 1100 DD Amsterdam, The Netherlands

2 Department of Surgery, Spaarne Gasthuis, P.O. Box 770, 2130 AT Hoofddorp, The Netherlands

3 Emergency Department, Amsterdam UMC, Location Academic Medical Center, University of Amsterdam, P.O. Box 22660, 1100 DD Amsterdam, The Netherlands

4 Department of Surgery, Tergooi Hospitals, P.O. Box 10016, 1201 DA Hilversum, The Netherlands

5 Department of Surgery, Onze Lieve Vrouwe Gasthuis, P.O. Box 95500, 1090 HM Amsterdam, The Netherlands

6 Department of Trauma and Hand Surgery, Maasstad Hospital, P.O. Box 9100, 3007 AC Rotterdam, The Netherlands 